\title{
Effect of surgical training on outcome and hospital costs in coronary surgery
}

\author{
A T Goodwin, I Birdi, T P J Ramesh, G J Taylor, S A M Nashef, J J Dunning, S R Large
}

\begin{abstract}
Background-There is a perceived conflict between the need for service provision and surgical training within the National Health Service (NHS). Trainee surgeons tend to be slower (thereby reducing theatre throughput), and may have more complications (increasing hospital stay and costs). Objective-To quantify the effect of training on outcome and costs.

Design-Data on 2740 consecutive isolated coronary artery bypass (CABG) operations were analysed retrospectively. Redo and emergency procedures were excluded. The seniority of the operating surgeon was related to operating times, risk stratified outcome, and overall hospital costs.

Setting-Regional cardiothoracic surgery unit.

Main outcome measures-Postoperative mortality; hospital costs.

Results-Consultants, senior trainees, intermediate trainees, and junior trainees performed 1524, 759, 434, and 23 procedures, respectively. Trainees at the three different levels were directly supervised by a consultant in $55 \%, 95 \%$, and $100 \%$ of cases. The unadjusted mortalities were $3.2 \%, 2.0 \%, 2.3 \%$, and $4.3 \%$, respectively (NS). There were no significant differences between the groups with respect to time in the intensive care unit and length of hospital stay. The mean cost per patient was $£ 6619, £ 6572, £ 6494$, and $£ 6404$ (NS).

Conclusions-Trainees performed $44.4 \%$ of all CABG operations. There was no detrimental effect on patient outcome, length of hospital stay, or overall hospital costs. There need be little conflict between service and training needs, even in hospitals with extensive training programmes.
\end{abstract}

(Heart 2001;85:454-457)

Keywords: coronary artery bypass surgery; training; costs

There is a perceived conflict between the need for service provision and surgical training within the National Health Service (NHS). Consultants face a dilemma between their duty to deliver the highest possible standard of care to their patients and their duty to teach and train their junior staff. ${ }^{1}$ Trainee surgeons tend to be slower (thereby reducing theatre throughput), and may have a higher complication rate (increasing hospital stay and costs). However, in the modern businesslike NHS there is intense pressure to increase throughput and reduce costs.

Since the implementation of the Calman report on the training of specialist registrars there has been an estimated $60 \%$ reduction in the time available for training. ${ }^{2-4}$ It is vital, therefore, that future consultants are exposed to the highest standards of training. Since the recent publicity surrounding the audit of surgical results in general, and in particular cardiothoracic surgeons, ${ }^{5}$ it is perhaps desirable that the performance of consultants and trainees is regularly audited. Despite this, there have been very few published reports comparing consultant and trainee outcomes. ${ }^{6-8}$ In addition, there are no studies examining the effect of trainee operating on overall hospital costs per patient. We therefore sought to quantify the effect of training on outcome and costs in patients undergoing coronary artery surgery.

\section{Methods}

We analysed data on 2740 consecutive, isolated coronary artery bypass (CABG) operations. All redo and emergency operations were excluded. Operations were performed between April 1996 and September 1998. Data were collected from the computerised theatre records (entered at the time of surgery) in which operation details, operating surgeon (defined as the surgeon performing the coronary anastomoses), theatre times, and risk factors (allowing Parsonnet risk scoring) were recorded. Risk data were entered at the time of surgery by the consultant anaesthetist. Details on the length of intensive care unit (ICU) stay, hospital stay, and 30 day mortality were obtained from the hospital admissions computer. These data are the subject of a three monthly surgical audit and were $100 \%$ complete. Consultant supervision was defined as a case in which the consultant was scrubbed and acted as first assistant. An estimate of the cost for each patient was based on the addition of variable costs ( $£$ /theatre minute, ICU hour, hospital day) to fixed costs (theatre and bypass disposables, medical staff, administration), as previously described. ${ }^{9}$

STATISTICAL ANALYSIS

The data were analysed according to the seniority of the operating surgeon. The study overlaps with the implementation of the Calman specialist registrar grade. In view of this, a senior trainee was considered to be either the old style senior registrar or the new specialist registrars in years 4-6 of specialist training. An intermediate trainee was defined as a trainee in years $1-3$ of specialist training. 
Table 1 Effect of seniority of operating surgeon on theatre times, hospital stay, and overall cost per patient

\begin{tabular}{|c|c|c|c|c|c|c|c|c|c|}
\hline & Cases & Bypass (min) & $\begin{array}{l}\text { Cross clamp } \\
\text { (mins) }\end{array}$ & $\begin{array}{l}\text { Grafts } \\
\text { (mean) }\end{array}$ & $\begin{array}{l}\text { Time/graft } \\
\text { (mins) }\end{array}$ & $\begin{array}{l}\text { Theatre time } \\
\text { (mins) }\end{array}$ & $\begin{array}{l}\text { ITU stay } \\
\text { (hours) }\end{array}$ & $\begin{array}{l}\text { Hospital stay } \\
\text { (days) }\end{array}$ & $\begin{array}{l}\text { Cost } \\
\text { (f/patient) }\end{array}$ \\
\hline Consultant & 1524 & $70.8(0.8)$ & $36.2(0.4)$ & $3.3(0.03)$ & $11.4(0.1)$ & $179(1.5)$ & $27.6(1.0)$ & $8.2(0.1)$ & $f 6620(54)$ \\
\hline Senior trainee & 759 & $73.7(0.8)$ & $40.6(0.5)^{\star \star \star}$ & $3.2(0.03)$ & $13.1(0.1)^{\star \star \star}$ & $171(1.6)^{\star \star}$ & $27.5(1.6)$ & $8.3(0.2)$ & $£ 6572(81)$ \\
\hline Intermediate trainee & 434 & $78.4(1.2)^{\star \star \star}$ & $43.5(0.7)^{\star \star \star}$ & $3.2(0.05)$ & $14.2(0.2)^{\star \star \star}$ & $188(3.0)^{\star}$ & $23.7(1.0)$ & $8.3(0.3)$ & $£ 6494(64)$ \\
\hline Junior trainee & 23 & $79.7(4.4)$ & $44.6(2.4)^{\star}$ & $2.9(0.15)$ & $15.7(0.5)^{\star \star \star \star}$ & $189(6.1)$ & $23.0(2.4)$ & $7.1(0.3)$ & f6404 (145) \\
\hline
\end{tabular}

Values are mean (SEM).

${ }^{\star} \mathrm{p}<0.05 ;{ }^{\star \star} \mathrm{p}<0.01 ;{ }^{\star \star \star} \mathrm{p}<0.001, v$ consultant.

Table 2 Proportion of cases assisted by consultant

\begin{tabular}{lclc}
\hline & Cases & $\begin{array}{l}\text { Assisted by } \\
\text { consultant } \\
(n)\end{array}$ & $\begin{array}{l}\text { Assisted by } \\
\text { consultant } \\
(\%)\end{array}$ \\
\hline Senior trainee & 759 & 415 & 55 \\
Intermediate trainee & 434 & 413 & 95 \\
Junior trainee & 23 & 23 & 100 \\
\hline
\end{tabular}

Table 3 Predicted $v$ actual mortality

\begin{tabular}{lll}
\hline & $\begin{array}{l}\text { Predicted } \\
\text { mortality (\%) }\end{array}$ & $\begin{array}{l}\text { Actual mortality } \\
\text { (\%) }\end{array}$ \\
\hline Consultant & $7.4(0.2)$ & $3.2(0.5)$ \\
Senior trainee & $6.7(0.2)$ & $2.0(0.5)$ \\
Intermediate trainee & $6.6(0.3)^{\star}$ & $2.3(0.7)$ \\
Junior trainee & $7.4(1.4)$ & $4.3(4.3)$ \\
\hline
\end{tabular}

Values are mean $(\mathrm{SEM})$

${ }^{\star} \mathrm{p}<0.05 v$ consultant.

The final group of junior trainees included both basic surgical trainees and specialist senior house officers (those with a stated interest in pursuing a career in the specialty).

The seniority of the surgeon was related to theatre times, ICU stay, hospital stay, Parsonnet score, and mortality. Parsonnet score is calculated preoperatively and gives an estimated percentage risk of mortality. ${ }^{10}{ }^{11}$ In addition, the duration of cardiopulmonary bypass, cross clamp time (duration of cardiac ischaemia), and the numbers of bypass grafts performed were analysed. The mean time taken to perform each bypass graft was calculated. Results are expressed as mean (SEM). Data were compared by one way analysis of variance, with post hoc testing using a Bonferoni correction where appropriate.

\section{Results}

EFFECT OF SENIORITY ON THEATRE TIMES AND HOSPITAL STAY

The results are summarised in table 1 . Consultants performed $55.6 \%$ of operations. The proportion of cases assisted by the consultant is shown in table 2. There was no significant difference in the number of grafts performed between consultants and trainees. However, the consultants were significantly quicker in terms of total bypass time, cross clamp time, and overall time for grafting. Interestingly, the senior trainees were eight minutes

Table 4 Actual mortality according to preoperative assessment of risk of death

\begin{tabular}{lllll}
\hline Risk & Consultant & Senior trainee & $\begin{array}{l}\text { Intermediate } \\
\text { trainee }\end{array}$ & Total \\
\hline Low $(0-4 \%)$ & $5 / 610(0.8 \%)$ & $2 / 347(0.6 \%)$ & $3 / 188(1.6 \%)$ & $10 / 1152(0.9 \%)$ \\
Fair $(5-9 \%)$ & $12 / 393(3.1 \%)$ & $4 / 182(2.2 \%)$ & $3 / 125(2.4 \%)$ & $19 / 710(2.7 \%)$ \\
Poor $(10-14 \%)$ & $11 / 273(4.0 \%)$ & $2 / 126(1.6 \%)$ & $3 / 64(4.7 \%)$ & $17 / 468(3.6 \%)$ \\
High $(15-19 \%)$ & $15 / 153(9.8 \%)$ & $3 / 64(4.7 \%)$ & $1 / 46(2.2 \%)$ & $19 / 263(7.2 \%)$ \\
Extremely high $(>20 \%)$ & $5 / 73(6.8 \%)$ & $4 / 30(13.3 \%)$ & $0 / 9(0.0 \%)$ & $9 / 113(8.0 \%)$ \\
\hline Values are number of deaths/total number of cases and (\% mortality). All values are \\
non-significant $v$ consultant.
\end{tabular}

quicker than consultants in terms of total theatre time $(\mathrm{p}=0.006)$, and 17 minutes quicker than the intermediate trainees $(p<0.001)$.

There were no differences between the different grades of surgeon in the mean length of ICU or hospital stay. The minimum and maximum ICU stays were 0 to 743 hours, 0 to 767 hours, 1 to 239 hours, and 9 to 67 hours for consultants, senior trainees, intermediate trainees, and junior trainees, respectively. Likewise, the minimum and maximum hospital stays were 0 to 53 days, 0 to 47 days, 0 to 66 days, and 4.9 to 10 days.

HOSPITAL COSTS

There was no significant difference in mean cost/patient between the consultants and junior surgeons (table 1).

\section{MORTALITY AND OUTCOME}

The predicted and actual mortality figures for each grade of surgeon are shown in table 3.

The predicted mortality for the patients operated on by consultants tended to be higher than senior trainees $(p=0.07)$ and intermediate trainees $(p=0.05)$. The mean predicted mortality for the junior trainee cases was the same as for the consultants; however, the number of patients was small.

There was no significant difference in actual mortality between the different grades of surgeons $(p=0.32)$. In order to try to remove any bias caused by differences in work load with respect to operative risk, we performed analysis of variance adjusting for the Parsonnet score. This also showed that the seniority of the operating surgeon was not related to actual mortality $(\mathrm{p}=0.57)$.

The data were also reanalysed following stratification according to preoperatively assessed risk of death (table 4). Risk of death was stratified into five groups as previously described ${ }^{9}$ : low risk (Parsonnet 0-4\%), fair risk (5-9\%), poor risk (10-14\%), high risk $(15-19 \%)$, and extremely high risk ( $\geqslant 20 \%)$. The number of cases performed by junior trainees were too small for analysis (just one death in the poor risk group overall). There was still no difference in mortality between consultants and trainees following risk stratification (Pearson's $\chi^{2}$, NS).

Table 5 Morbidity according to the seniority of the operating surgeon

\begin{tabular}{lll}
\hline & Bleeding & Wound infection \\
\hline Consultant & $60(3.9 \%)$ & $15(1.0 \%)$ \\
Senior trainee & $18(2.4 \%)$ & $5(0.7 \%)$ \\
Intermediate trainee & $20(4.6 \%)$ & $5(1.2 \%)$ \\
Junior trainee & $1(4.3 \%)$ & $0(0.0 \%)$ \\
\hline
\end{tabular}

Values are total number of patients (\%).

All values are non-significant $v$ consultant. 
Table 6 Place of discharge according to the seniority of the operating surgeon

\begin{tabular}{lllll}
\hline & Home & Convalescence & Hospital & Died \\
\hline Consultant & $1331(87 \%)$ & $102(7 \%)$ & $43(3 \%)$ & $48(3 \%)$ \\
Senior trainee & $671(88 \%)$ & $58(8 \%)$ & $15(2 \%)$ & $15(2 \%)$ \\
Intermediate trainee & $388(90 \%)$ & $28(6 \%)$ & $8(2 \%)$ & $10(2 \%)$ \\
Junior trainee & $22(96 \%)$ & 0 & 0 & $1(4 \%)$ \\
\hline Valo & & &
\end{tabular}

The morbidity and final place of discharge according to seniority of surgeon is shown in tables 5 and 6 . There were no differences in rates for bleeding (defined as patients returning to theatre for re-exploration) between the groups. Likewise, there was no difference in the rates of deep sternal infection or mediastinitis (defined as patients requiring return to theatre for debridement or rewiring). Most patients were discharged home or to convalescence. A few (less than 3\%) were discharged to other hospitals. There was no difference in the place of discharge between consultants and trainees.

\section{Discussion}

In patients undergoing coronary artery bypass surgery there is no difference in hospital costs or overall mortality when the results of trainee operators are compared with those of consultants. These findings are in conflict with the widely perceived view that trainee surgeons may be detrimental to patient outcomes and overall hospital costs. The only significant differences were that consultant surgeons tended to be quicker at performing the coronary anastomoses. In terms of overall time in theatre, operations performed by consultants were only nine minutes quicker than those by intermediate trainees. In a typical operating day in our institution there are two to three CABG operations performed in each theatre. If half these operations are performed by the trainee this will mean an additional 9.0 to 13.5 minutes of theatre time a day.

This study was non-randomised and retrospective in nature. It was impossible to compare accurately the mortality figures between consultants and trainees. Higher risk cases or more technically demanding cases will have been selectively performed by the consultants, and this is reflected in the higher mean Parsonnet scores. However, Parsonnet risk scores (the most widely used system in the UK) do not include factors such as severity of disease in the distal coronary vessels. These factors make the surgery technically more demanding, but do not increase the risk score.

The procedure was performed by junior trainees in only a few cases. This is a potential source of bias, although the results agree with the trend shown among the more senior trainees. A cynic might conclude that coronary artery surgery can be quickly mastered to a satisfactory level by even very junior trainees and that the six years spent in higher surgical training is too long. But this is obviously not the case as the consultants are quicker than even the most senior trainees at performing the most complex part of the operation (the coronary anastomosis). This would suggest that manual dexterity and technical ability continue to improve throughout the training period and maybe even after consultant appointment. It also fails to recognise the high levels of supervision that the trainees receive.

This study does, however, represent what actually happens in day to day practice. In addition, the numbers of patients analysed is large. CABG surgery is a relatively long procedure with multiple complex steps. The standard practice in our hospital, and in most others in the UK, is for the trainee to perform the peripheral parts of the operation (conduit harvest, preparation for cardiopulmonary bypass, and chest closure) with the consultant coming in to perform, or assist at, the cardiac part of the procedure. Not surprisingly, therefore, the differences in operating times seen are for bypass time and cross clamp time. Although shorter cross clamp and bypass times are desirable, the longer times taken by trainees are well within acceptable limits and are unlikely to be clinically significant. The overall times in theatre do, however, reflect a realistic time for procedures performed by a surgical team consisting of a consultant and a trainee. We are currently undertaking a prospective trial of outcome and costs in which a consultant or supervised trainee performs the operation from initial skin incision to skin closure. This will allow us to determine more accurately the overall effect of having trainees in an institution, and whether other measures of outcome-such as myocardial infarction, postoperative bleeding and wound infection-are affected.

There were no staffing differences depending on whether the operation was performed by a consultant or a trainee. No operations were performed without the consultant being present on site at the hospital (including all "unsupervised" cases by the senior trainees). The costs of the operation overall could be reduced by removing trainees altogether from a hospital and using just consultants aided by surgical assistants. However, this would be very short sighted. Without training there will be no future surgeons. ${ }^{1}$ The answer is to establish the true cost of training tomorrow's surgeons and to find a balance between appropriate apportionment of consultant time to training and service delivery.

It must be emphasised that training in this institution is very closely supervised, with $70 \%$ of all trainee operations being performed under consultant supervision and over $95 \%$ in the case of junior trainees. Our findings cannot be extrapolated to training programmes of the "see one, do one, teach one" variety. The practice of junior surgeons operating unsupervised is no longer tenable. ${ }^{12}$ This should not necessarily mean that consultants should do more operating, but rather that juniors should be better supervised.

There are published reports suggesting that long term outcomes are poorer in patients undergoing hip replacement surgery performed by trainees compared with consultants. ${ }^{13}$ In particular, the risk of a hip requiring revision surgery during a five year study was 11 times greater if the initial operation had been performed by a trainee surgeon. The highest 
risk period for patients undergoing coronary surgery is the first 30 days following surgery, and we have not been able to show any difference in outcome during this period. It is possible, however, that with long term follow up a difference in the numbers of patients requiring redo coronary surgery will become apparent. It is too early to determine this from our database at present, as typically patients do not present for redo surgery until 10 years after the original operation.

CONCLUSIONS

Trainees at our institution perform $44.4 \%$ of all CABG operations. There was no detrimental effect on patient outcome, length of hospital stay, or hospital costs. This study suggests that there need be little conflict between service and training needs, even in hospitals with extensive training programmes. We believe that there is no reason why these results should not be applicable to supervised trainees learning to perform operations and procedures (such as coronary angioplasty) in other specialties. However, further research is required to examine whether this is indeed the case.
1 Hargreaves $\mathrm{DH}$. A training culture in surgery, $B M 7$ 1996;313:1635-9.

2 Calman K. Hospital doctors: training for the future. The report of the working group on specialist medical training. London: Health Publications Unit, 1993.

3 Crofts TJ, Griffiths JMT, Sharma S, et al. Surgical training: an objective assessment of recent changes for a single health board. BMF 1997;314:891-5.

4 Bulstrode C, Holsgrove G. Education for educating surgeons. BMf 1996;312:326-7.

5 Treasure T. Lessons from the Bristol case. BMF 1998;316: 1685-6.

6 Brittenden J, Bradbury AW, Murie JA, et al. Training in carotid endarterectomy (CEA) can be safe given adequate supervision [abstract]. Br F Surg 1997;84(suppl 1):68.

7 Aitken RJ. Surgical trainees performing colorectal cancer resections achieve results as good as their consultants [abstract]. Br F Surg 1997;84(suppl 1):56-7.

8 Anderson JR, Parker DJ, Unsworth-White MJ, et al. Training surgeons and safeguarding patients. Ann $R$ Coll Surg Engl 1996;78(suppl 3):116-18.

9 Barlow CW, Imber CJ, Sharples LD, et al. Cost implications of mitral valve replacement versus repair in mitral regurgitation. Circulation 1997;96(suppl II):II-90-5.

10 Parsonnet V, Dean D, Bernstein AD. A method of uniform stratification of risk for evaluating the results of surgery in acquired adult heart disease. Circulation 1989;79(suppl I):I-3-12.

11 Nashef SA, Carey F, Silcock MM, et al. Risk stratification for open heart surgery: trial of the Parsonnet system in a British hospital. BMF 1992;305:1066-7.

12 Collins C. Surgical training, supervision, and service. BMF 1999;318:682-3.

13 Marston RA, Cobb AG, Bentley G. Stanmore compared with Charnley total hip replacement. A prospective study of 413 arthroplasties. F Bone foint Surg (Br);78B:178-84.

\section{IMAGES IN CARDIOLOGY}

\section{An unusual (subcarinal) case of pulmonary artery sling}

A 3 month old boy was referred because of pronounced dyspnoea. Bronchoscopy revealed a normal upper airway and tracheal bifurcation. The left main bronchus was compressed to $80 \%$ of its diameter and the lung lobulation was normal. Echocardiography showed a pulmonary artery sling. Frontal angiography of the main pulmonary artery (right) confirmed the anomalous and low origin of a good sized left pulmonary artery (LPA) from the right pulmonary artery (RPA). The patient underwent operative repair under cardiopulmonary bypass with detachment of the aberrant LPA and its implantation into the main pulmonary artery. $\mathrm{He}$ is currently doing well without respiratory medication nine months after surgery.

In the pulmonary artery sling, supracarinal or carinal crossing of the LPA causes airway obstruction at the level of the trachea. Isolated subcarinal crossing of the LPA causing left main bronchus obstruction like our case is exceptional. Definite diagnosis with delineation of vascular anatomy is made by pulmonary angiography combined or completed with tracheobronchoscopy to demonstrate the airway compression and the associated tracheal anomalies. Echocardiography allows diagnosis of pulmonary artery sling but is not always predictive, and

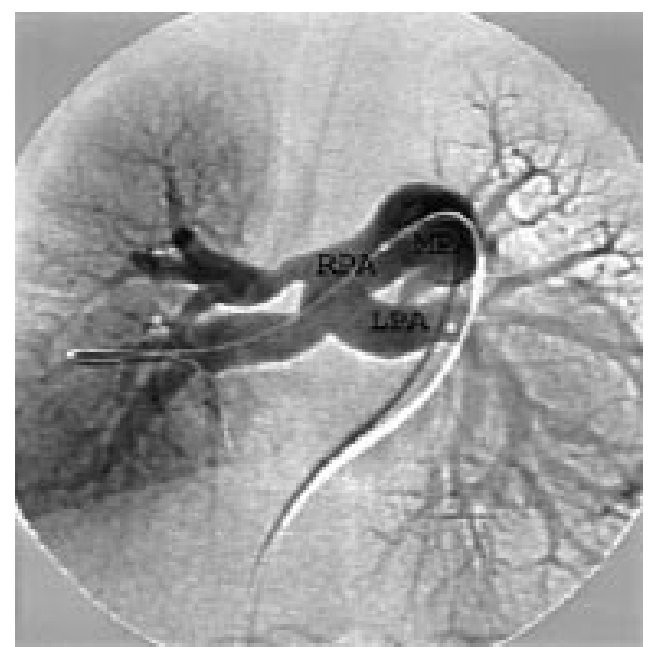

anterior indentation of the oesophagus but does not show the anatomy. Computed tomography and magnetic resonance imaging delineates pulmonary artery sling, but they are often difficult to perform in uncooperative infants.

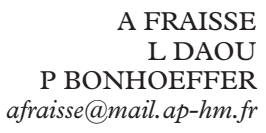

